\title{
Morbidity Pattern among Under-five Children of Market Women in Ibadan
}

\author{
FO Omokhodion*,A Oyemade**, MKC Sridhar ${ }^{+}$
}

\begin{abstract}
Summary
Omokhodion OF, Oyemade A, Sridhar MKC. Morbidity Pattern among Under-five Children of Market Women in Ibadan. Nigerian Journal of Paediatrics 2003; 30:135.

Background: The study was carried out in two large markets in Ibadan, namely: Bodija, a predominantly food market with poor environmental sanitation, and Gbagi, a textile market with a cleaner environment.

Objectives: To compare the morbidity patterns among under-five children of traders in both markets.

Design: A cross sectional study design was utilized.

Patients and Participants: Mothers with under-five children in the two markets.

Method: A structured questionnaire was administered to mothers of under-five children in both markets to obtain information about immunization and childhood illnesses among their children. A physical examination was also carried out on each index child.

Results: A total of 232 and 219 children were seen in Bodija and Gbagi markets, respectively. Mothers in Gbagi had higher educational attainment than those in Bodija. Mothers' reports of fever, cough and diarrhoea affecting their children indicated a similarity in the prevalence of these symptoms among children in both markets. However, physical examination revealed that the children in Bodija had more signs of morbidity compared to those in Gbagi. The prevalences of anaemia, malaria parasitaemia and ascariasis were 28 percent, 20 percent and eight percent in Bodija, while the corresponding figures for Gbagi were eight percent, 17 percent and two percent $(p<0.05)$.

Conclusion: Low educational status and poor environmental sanitation may put children at risk of childhood diseases. Improvement of environmental sanitation in large markets such as Bodija should improve the health of the traders, and the public, and also reduce morbidity due to childhood illnesses among the children of the traders.
\end{abstract}

\section{Introduction}

DESPITE several programmes aimed at promoting child survival, childhood morbidity and mortality continue to be an issue of major concern in Nigeria. Many of the child survival programmes are child or mother-oriented, with little emphasis placed on the physical and biological environment in which the child grows. Childhood exposure to adverse environmental

\section{University College Hospital, Ibadan}

Department of Community Medicine

*Senior Lecturer

${ }^{*}$ Retired Professor

Department of Epidemiology, Medical Statistics and Environmental Health

+ Professor

Correspondence: Dr FO Omokhodion factors may occur inside or outside the home. The influence of environmental factors in the home on childhood morbidity due to diarrhoea has been documented. ${ }^{1-3}$ Therefore, this study did not focus on the home environment. Exposure to adverse environmental factors outside the home occurs when mothers, especially those in the lower socioeconomic class, take their children to work outside the home. Often, these mothers, unlike their counterparts in the higher socioeconomic class, cannot afford the cost of child care centres and are forced to take their young children to their workplaces, thereby exposing them to hazards outside the home. In Ibadan, the majority of women in this category are petty traders, some of whom sell their wares in large markets characterized by unsanitary environmental conditions. Thus, in addition to exposure to prevailing health hazards in 
the home environment, these children are also exposed to environmental hazards in the market. This study sought to determine the effects of the adverse environmental conditions in the market on the health of these children. It describes the morbidity pattern among children aged less than five years in two large markets, each with a different state of environmental sanitation.

\section{Subjects and Methods}

This cross-sectional study was carried out between September 1996 and March 1997 at Bodija and Gbagi markets, both situated in different areas of Ibadan. Bodija market is predominantly a food market with 3,596 stalls, while Gbagi is mainly a textile market with 2,853 stalls. Gbagi market is clean and well laid out with tarred roads, good drainage, and an effective refuse disposal system. Bodija market, on the other hand, is overcrowded, with more than half of the traders displaying their food items along the roadside, away from the designated stalls; the roads are untarred and littered with refuse resulting in poor environmental sanitation in the market.

Permission to carry out the study was obtained from the chairmen of the two local government areas. In addition, the leaders of the Market Women Association in each market were contacted to discuss the objectives of the study and to obtain their consent. Informed consent was also obtained from the mothers who participated in the study. Each market is divided into blocks of stalls that are numbered in serial order. Only those mothers whose children, aged less than five years, had been staying with them in the market for at least, six months, were included in the survey. Sample size estimation using a formular for a descriptive study gave a minimum sample size of $\mathbf{2 6 0}$ for each group. Stalls were selected using a systematic random-sampling technique in which every seventh stall was chosen. Where no child aged less than five years was found in a particular stall, the next stall was selected. In all, 266 mothers in Bodija and 260 in Gbagi markets were included in the survey. They were interviewed by trained interviewers using a structured questionnaire. This questionnaire was pre-tested on 20 mothers in another market before the main study. The questionnaire sought information on social and demographic characteristics of respondents, the number of children they had, age of the under-five child staying with them in the market, immunization status of the child and a report of illnesses in the child in the last three months A general physical examination was carried out on each child; this was followed by an estimation of the packed cell volume (PCV) and examination of stool samples for helminths.

\section{Statistical analysis}

Questionnaires were coded and statistical analysis was carried out using EPI Info version 6.02 software to calculate frequencies. Contingency chi-square analysis was used to check association between categorical variables.

\section{Results}

The age distribution and educational status of mothers in the two markets are shown in Tables I and II, respectively. The age distribution of mothers in the two markets was similar. With regard to educational status, only 36 percent of mothers in Bodija had at least, secondary education, while 65 percent of mothers in Gbagi were in this category (Table II; $\mathrm{p}<0.001$ ). In Bodija, 232 children aged less than five years were seen

Table I

Age Distribution of Mothers in the Two Markets

\begin{tabular}{|c|c|c|}
\hline Mother's Age (Yrs) & Bodija (\%) & Gbagi (\%) \\
\hline$<21$ & $13(4.9)$ & $5 \quad(1.9)$ \\
\hline $21-25$ & $58(21.8)$ & $72(27.7)$ \\
\hline $26-30$ & $89(33.5)$ & $94(36.1)$ \\
\hline $31-35$ & $72 \quad(27)$ & $59(22.7)$ \\
\hline $36-40$ & $28(10.5)$ & $25(9.6)$ \\
\hline $41-45$ & $4(1.5)$ & $3(1.2)$ \\
\hline $46-50$ & $2(0.8)$ & $0 \quad(0)$ \\
\hline$>50$ & $0 \quad(0)$ & $2 \quad(0.8)$ \\
\hline Total & $266(100)$ & $260(100)$ \\
\hline
\end{tabular}

$\mathrm{X}^{2}=0.42 ; P=0.52$

Table II

Mothers' Educational Status

\begin{tabular}{llc} 
Educational Status & Bodija (\%) & Gbagi (\%) \\
\hline No formal education & $57(21)$ & $27(10)$ \\
Some primary & $32(12)$ & $23(9)$ \\
Completed primary & $81(31)$ & $42(16)$ \\
Some secondary & $29(11)$ & $47(18)$ \\
Completed secondary & $62(23)$ & $100(39)$ \\
Higher education & $5(2)$ & $20(7.7)$ \\
No response & $0(0)$ & $1(0.3)$ \\
\hline Total & $266(100)$ & $260(100)$ \\
\hline
\end{tabular}

$X^{2}=46.64 ; P=0.0001$ 
Table III

Age Distribution of the Under-five Children

\begin{tabular}{lll}
\hline Age & Bodija (\%) & Gbagi (\%) \\
\hline $0-5$ months & $13(6)$ & $22(10)$ \\
$6-11$ months & $63(27)$ & $73(33)$ \\
$12-23$ months & $83(36)$ & $79(36)$ \\
$24-35$ months & $56(24)$ & $25(12)$ \\
$36-47$ months & $14(6)$ & $15(7)$ \\
$48-59$ months & $3(1)$ & $5(2)$ \\
\hline Total & 232 & 219 \\
\hline
\end{tabular}

$X^{2}=9.03 ; P=0.107$

Table IV

Mothers' Response about Immunization Status of their Under-five Children

\begin{tabular}{lcc} 
Immunization Status & Bodija $(\%)$ & Gbagi $(\%)$ \\
\hline Complete for age & $160(60)$ & $164(63)$ \\
Not complete for age & $86(32)$ & $72(28)$ \\
No response & $20(8)$ & $24(9)$ \\
\hline Total & $266(100)$ & $260(100)$ \\
\hline
\end{tabular}

$\mathrm{X}^{2}=1.59 ; \mathrm{P}=0.452$

Table V

Mothers' Knowledge about Diseases preventable by
Immunization

\begin{tabular}{lcl}
\hline Disease & $\begin{array}{c}\text { No. of mothers who } \\
\text { knew } \begin{array}{l}\text { Bodija }[n=266] \\
(\%)\end{array}\end{array}$ & $\begin{array}{l}\text { Gbagi } \\
{[n=260]} \\
(\%)\end{array}$ \\
\hline Tuberculosis & $200(75)$ & $189(73)$ \\
Polic & $213(80)$ & $197(76)$ \\
Tetanus & $142(53)$ & $157(60)$ \\
Whooping cough & $65(24)$ & $61(23)$ \\
Measles & $35(13)$ & $40(15)$
\end{tabular}

$X^{2}=2.06 ; P=0.725$

during the survey. They comprised 123 (53 percent) males and 109 (47 percent) females; corresponding figure for Gbagi was 219, of whom 108 (49 percent) were males and 111 ( 51 percent) females. Table III shows that there was no difference' in the age distribution of the children in the two markets $(p>0.5)$.

\section{Immunization Status}

Table IV shows the immunization status of the children. In Bodija, 160 (60 percent) of the children had completed the immunization schedule corresponding to their age; this was similar to the 164 (63 percent) in Gbagi $(p>0.05)$. Some of the reasons given for non-completion of the immunization schedule were that the mother forgot (19.4 percent in Bodija and 14.5 percent in Gbagi) and that the relevant vaccine was not available (12.6 percent in Bodija and 25 percent in Gbagi). Enquiry about mothers' knowledge of the benefits of immunization revealed that 225 (85 percent) women in Bodija and 233 (90 percent) women in Gbagi knew that immunization protects against diseases. 'The mothers' knowledge of protection for specific diseases is shown in Table V. These results show that while the majority of mothers knew that immunization protects against tuberculosis, polio and tetanus, few mothers knew that immunization protects against whooping cough and measles. The differences observed in the two markets were however, not significant $(p>0.05)$.

\section{Morbidity Pattern}

Mothers' responses to enquiry about the history of fever, cough and diarrhoea revealed that in Bodija, 166 (62 percent) mothers indicated that their child had had fever in the last three months, compared with 167 (57 percent) mothers in Gbagi. The corresponding figures for cough were 99 (37 percent) in Bodija and 119 (46 percent) in Gbagi, and for diarthoea, 82 ( 31 percent) in Bodija and 87 ( 33 percent) in Gbagi. The differences in the occurrence of fever, cough and diarrhoea among the under-fives in the two markets were not significant $(p>0.05)$. In Bodija, 16 (seven percent) of the mothers indicated that their children had been admitted to the hospital in the last three months compared with 23 (nine percent) of mothers in Gbagi. The commonest illnesses that led to hospital admission in both markets were fever, diarrhoea and measles.

Abnormal findings on physical examination of the children are presented in Table VI. The results show that signs of morbidity were more prevalent among the children in Bodija market $(p<0.05)$. Scarification marks and female circumcision were also more prevalent among them $(p<0.05)$. Forty-seven $(28$ percent) children in Bodija had a packed cell volume less than 30 percent while 17 (eight percent) children in Gbagi were in this category. Malaria parasites were found in the blood film of 52 (20 percent) of the Bodija children and 38 (17 percent) of Gbagis. Ova of Ascaris 
Table VI

Physical Examination Findings in Underfive Children

\begin{tabular}{lccc}
\hline & $\begin{array}{c}\text { Bodija }[n=232] \\
\text { Percent) }\end{array}$ & Gbagi $[n=219]$ & Total(Percent) \\
\hline Umbilical hernia & $32(14)$ & $39(18)$ & 71 \\
Fernale circumcision & $48(21)$ & $7(3)$ & 55 \\
Scarification marks & $26(11)$ & $14(6)$ & 40 \\
Splenomegaly & $7(3)$ & $11(5)$ & 18 \\
Inguinal lymphadenopathy & $14(6)$ & $2(1)$ & 16 \\
Pallor & $12(5)$ & $1(0.5)$ & 13 \\
Hepatomegaly & $4(2)$ & $1(0.5)$ & 5 \\
Fever & $1(0.4)$ & $2(1)$ & 3 \\
Runny nose & $3(1)$ & $0(0)$ & 3 \\
Measles rash & $0(0)$ & $2(1)$ & 2 \\
\hline
\end{tabular}

were found in the stools of 20 children (eight percent) in Bodija, and in five (two percent) Gbagi children $(p<0.05)$.

\section{Discussion}

The immunization rates of 60 percent and 63 percent recorded in this study are similar to that reported in a study in Jos where 62.4 percent of under-fives had completed immunization for their age. ${ }^{4}$ This suggests that about two thirds of under-fives are protected against childhood diseases. In spite of educational differences, there was no difference in mothers' knowledge about protection against childhood diseases by vaccination. Mothers in both markets were knowledgeable about protection afforded by vaccination against tuberculosis, polio and tetanus. However, knowledge about protection against measles and whooping cough was deficient. A report from Maiduguri indicated that only one percent of women knew that measles could be prevented by vaccination. ${ }^{5}$ These findings highlight the need for improvement in the health education of mothers about the role of vaccines in the prevention of childhood diseases. especially measles.

Malaria, diarrhoea and acute respiratory infections are the commonest childhood illnesses in this environment. ${ }^{6-8}$ Mothers' report about the history of fever, cough and diarthoea in the last three months before the survey indicated that the prevalences of these symptoms in children in both markets were similar. In all, 60 percent of children had fever in the last three months, 41 percent had cough and 32 percent had diarrhoea. The National Demographic and Health Survey $2000,{ }^{9}$ reported that 30 percent of children had fever in the last two weeks and 15 percent had diarrhoea in the same period. This is an indication that the proportion of fever and diarhoea among the underfives in this study is similar to the national figures.

The most significant observations in this study were the findings on physical examination of the children. Under-five children in Bodija had more features of morbidity compared to those in Gbagi, the cleaner market. Anaemia, malaria parasitaemia and ascariasis were all more prevalent among children in Bodija market. This difference may be due to both environmental and socio-economic factors. Childhood morbidity has been associated with educational status. ${ }^{8,10}$ Thus, the lower educational status of mothers in Bodija may be associated with the observation of greater morbidity among their children. Environmental sanitation in Bodija market is very poor; in spite of this, it was common to find under-five children sitting or crawling on the bare ground in the market. Such contact with the unsanitary environment may be responsible for the higher prevalence of ascariasis among these children.

The results of this study suggest that low educational status of women traders and poor environmental sanitation in the market may put children at risk of morbidity from childhood diseases. While the influence of the home environment on the health status of under-five children is well recognised, it is noteworthy that the majority of the mothers of these children spent between $8-10$ hours a day in the market; this is considerably more than is spent at home, apart from sleeping hours. Market women should be engaged in adult literacy programmes as this will improve their appreciation of health-related issues. The improvement of environmental sanitation in large markets like Bodija continues to pose a challenge to public health 
authorities in Nigeria. Apart from safeguarding the health of the traders and the public who purchase foods

\section{Acknowledgement}

This study was supported by a Senate Research Grant from the University of Ibadan.

\section{References}

1. Jinadu MK, Olusi SO, Agun JI, Fabiyi AK Childhood diarrhoea in rural Nigeria. Studies on prevalence, mortality and socio-environmental factors. J Diarrboeal Dis Res 1991; 9: 323-7.

2. Oni GA, Schumann DA, Oke EA. Diarthoeal disease morbidity, risk factors and treatments in low socioeconomic area of Ilorin, Kwara State, Nigeria. $J$ Diarrhoeal Dis Res 1991; 9 :250-7

3. Dikassa L, Mock N, Magnani R, Rice J, Abdoh A, Mercer $D$, Bertrand W. Maternal behavioural risk factors for severe childhood diarrhoeal disease in Kinshasa, Zaire. Int J Epidemiol 1993; 22: 327-33.

4. Angyo IA, Lawson JO, Okpeh ES, Pam SD. Sociodemographic factors affecting immunization status of hospitalized pre-school children. Nig.J Paediatr 1998; 25: 57-63.

5. Arube JP, Omotara BA, Mandu Baba. Perceptions, beliefs and practices of mothers in suburban and rural areas towards measles and measles vaccination in northern Nigeria. Trop Doct 2001; 31: 89-90.

6. Akang EE, Ekweozor $C$, Pindiga HU, Onyemenem TN. Childhood infections in Nigeria: an autopsy study. $J$ Trop Med Hyg 1993; 96: 231-6.

7. Hodges $M$, Williams RA. Registered infant and underfive deaths in Freetown, Sierra Leone from 1987-1991 and a compatison with 1969-1979. West Afr J Med 1998; 17: 95-8.

8. Muhe L, Byass P, Freij L, Sandstrom A, Wall S. A oneyear community study of under-fives in rural Ethiopia: patterns of morbidity and public health risk factors. Public Health 1995;109 : 99-109.

9. National Population Commission (Nigeria) 2000. Nigeria Demographic and Health Survey 1999.Calverton, Maryland: National Population Commission and ORC/ Macro.

10. Elegbe IA, Ojofeitimi EO, Elegbe I, Akinola MO. Pathogenic bacteria isolated from infant feeding teats: contamination of teats used by illiterate and educated nursing mothers in Ile-Ife, Nigeria. Am J Dis Child 1982; 136: 672-4. 